\title{
UM OLHAR SOBRE A AMAZÔNIA NA OBRA HISTÓRIA DE UM PESCADOR, DE INGLÊS DE SOUSA
}

\author{
ANA CLÁUDIA DIAS RIBEIRO ${ }^{1}$ \\ Instituto Federal de Ciência e Tecnologia de Rondônia \\ Av. Jorge Teixeira, 3146 - 76821-002 - Porto Velho - RO - Brasil \\ ana.ribeirodifro.edu.br
}

\begin{abstract}
RESUMO: O presente trabalho tem como objetivo fazer uma reflexão sobre como é construído o universo amazônico na obra "História de um Pescador", de Inglês de Sousa. Para tanto, consideramos o contexto histórico da Amazônia, o periodo em que se passa o enredo, analisando os aspectos da narrativa (linguagem, cultura e identidade), utilizando de autores como Gondim, Loureiro, Bhabha e Benchimol. Como resultados das análises verificamos que Sousa através de sua obra, faz uma denúncia social da exploração sofrida pelos caboclos, dos abandonados pelas autoridades. Além disso, percebemos a importância de conhecer melhor a cultura da Amazônia, descrita por quem conheceu essa realidade.
\end{abstract}

Palavras-chave: Amazônia; cultura; caboclo.

\begin{abstract}
This paper aims to reflect on how it is built the Amazon universe in the book "History of a Fisherman", English de Sousa. Therefore, we consider the historical context of the Amazon, the period in which it passes the plot, analyzing the aspects of narrative (language, culture and identity), using authors as Gondim, Loureiro, Bhabha and Benchimol. The results of the analyzes Sousa found that through his work, is a social denunciation of exploitation suffered by mestizos, the abandoned by the authorities. Also, we realize the importance of better understanding the culture of the Amazon, described by those who knew this reality.
\end{abstract}

Keywords: Amazon; culture; caboclo.

\section{Contextualizando}

O contato com o livro História de um Pescador ocorreu durante uma pesquisa, sobre autores que falassem sobre a Amazônia, conhecidos ou não pela academia. Assim, sua escolha se justifica por se tratar de uma obra pouco conhecida e analisada. Embora, Inglês de Sousa seja o único autor do norte reconhecido na História da Literatura Brasileira através de outra obra "O Missionário" (1891), canonizado romance naturalista.

O presente trabalho tem como objetivo fazer uma reflexão sobre como é

\footnotetext{
${ }^{1}$ Mestre em Letras pela UNIR; professora no Instituto Federal de Educação Ciência e Tecnologia de Rondônia (IFRO). http://lattes.cnpq.br/4976640769881483.
} 
construído o universo amazônico na obra História de um Pescador, de Inglês de Sousa. Para tanto, consideramos o contexto histórico da Amazônia, o período em que se passa o enredo, analisando os aspectos da narrativa (linguagem, características e cultura), utilizando de autores como Gondim, Loureiro, Bhabha e Benchimol.

O livro História de um Pescador foi escrito por Herculano Marcos Inglês de Sousa em 1876. E juntamente com os livros "O Coronel Sangrado", "Contos Amazônicos" e "O Cacaulista" faz parte do ciclo Cenas da vida do Amazonas. O autor nasceu em Óbidos/PA em 1853, morou em Manaus, Silves (AM), Vila Bela (hoje Parintins), Belém e São Luís. Com 14 anos foi estudar no Rio de Janeiro, período em que já escrevia romance, drama e poemas. Iniciou o curso de Direito no Recife, quando escreveu seu primeiro livro, "O Cacaulista”. Depois se transferiu para São Paulo onde concluiu o curso de Direito.

A literatura produzida na Amazônia costuma ser vista com certo receio e dificilmente autores amazônicos figuram entre os renomes nacionais. Por traz disso, talvez esteja os interesses econômicos divergentes: de um lado os que querem explorar os recursos naturais e receber em lucros; do outro, ambientalistas e defensores dos povos tradicionais. Embora o cenário seja a Amazônia, podemos afirmar que se trata de uma obra universal, visto que trata de questões como a exploração entre colonizadorcolonizado que coexiste ao redor do mundo.

O olhar lançado por Inglês de Sousa sobre a Amazônia é de um amazônida que apesar de ter saído daquela região na adolescência, não perde contato com suas raízes. Conhecedor da cultura e do estigma lançado sobre o caboclo da Amazônia que é retratado por diversos escritores, em diferentes obras em que

[...] vem embutida a ideia de superioridade captada nas expressões de debilidade ou pujança, degenerescência ou maturidade, indolência ou diligência, inferno ou paraíso, traição ou fidelidade, nomadismo ou inocência sem malícia, antropofagia, alcoolismo, belicosidade, inimizade, fetichismo, inconstância etc. etc., e o parâmetro de avaliação é o olhar dos que descobriram a totalidade que fazem parte. Até então formavam uma parte sem todo [...]. (GONDIM, 1994, p. 39)

Segundo Candido (2010) na análise do texto literário se deve observar, simultaneamente, forma e conteúdo. Isto porque o contexto, ou seja, o meio no qual o escritor está inserido, juntamente com sua história de vida, influências e conflitos sociais vivenciados interferem na criação do discurso. O escritor, portanto, representa não interesses individuais, mas interesses do grupo social a que ele pertence. Dessa forma, podemos afirmar que a obra ora analisada é resultado das influencias histórico-sociais vivenciadas por seu autor, somados a sua história de vida. O discurso que se vê é de alguém que representa o povo da Amazônia, que fala com conhecimento de causa da situação vivenciada. 


\section{Aspectos histórico-culturais da Amazônia}

Amazônia brasileira encontra-se distante dos grandes centros econômicoadministrativos do país, o que a torna segundo Loureiro (2000) uma região isolada. No entanto, essa perspectiva é antiga, vem do período da colonização portuguesa. Quando os europeus chegaram ao Brasil e se depararam com os indígenas que não possuíam o mesmo nível de desenvolvimento tecnológico dos padrões europeus, se consideravam superiores. Devemos lembrar a importante missão dos jesuítas que era de diminuir o isolamento geográfico, desbravando o extenso território brasileiro.

No entanto, em tempos de globalização, o isolamento da região diminui cada vez mais, ocasionando grandes consequências, pois reduz as populações tradicionais das florestas a favor do progresso econômico, levantando uma questão a respeito da formação de uma identidade cultural na região.

Segundo Hall, o sujeito é sociológico, assim sendo sua identidade é constituída por meio da "interação" entre o eu e a sociedade, pois "O sujeito ainda tem um núcleo ou essência interior que é o "eu real", mas este é formado e modificado num diálogo contínuo com os mundos culturais "exteriores" e as identidades que esses mundos oferecem" (HALL, 2011, p. 11).

O conceito de "identidade" aqui deve ser entendido não como algo acabado, terminado, mas como um processo, a identidade não é algo que se encerra em uma noção dada previamente, mas sim "algo que se constrói enquanto o sujeito compartilha, enquanto está posto em relação, nos levando a pensar nesse processo sempre em interface com a alteridade" (BOECHAT, 2011, p. 16). Portanto, nesse sentido, a Amazônia sempre teve uma identidade, mesmo quando não havia a predominância do idioma e cultura portugueses, afinal os variados povos que viviam nestas terras comprovam o compartilhamento, a construção de culturas e a citada "interface com a alteridade". A preocupação com uma "identidade regional" aflorou quando surgiu uma população mestiça e esta divergiu, dialeticamente e fisicamente, com o poder centralizador da administração do Estado brasileiro. Essa preocupação, em um primeiro momento, estaria muito mais atrelada aos interesses administrativos do Estado.

História de um Pescador é uma obra que retrata aspectos histórico-culturais da Amazônia do século XIX, destacando a diferença social, a exploração e abandono vivenciados pelo amazônidas.

A história do livro acontece no Grão-Pará, que compreendia a parte da Amazônia sob soberania portuguesa. Região de difícil acesso, a qual a dificuldade de penetração, geralmente, era justificada pela grandiosidade da floresta, umidade, chuvas, insetos, doenças, índios agressivos e outros imprevistos da natureza.

A Amazônia dependia quase que exclusivamente da floresta. Apesar de no final do século XIX, registrar-se no Pará, segundo Loureiro, pequena presença de criadores de gado. $\mathrm{O}$ homem da Amazônia mora numa região constantemente encharcada, formando um mundo de águas. Benchimol, assim descreve o modo de vida do caboclo:

com notável instinto de defesa e de aproveitamento dos recursos 
naturais. Vivendo em função do seu meio. Geográfica e vegetalmente. Dos peixes, dos rios, do pirarucu e do tambaqui, do jaraqui e do matrinchão; da farinha d'água e do seu roçado. (...) A "montaria" - uma esplêndida tradução antropogeográfica do veículo feito pelo caminho. Uma economia doméstica, cerrada, de insatisfação de suas necessidades. Sem estímulos, nem reações violentas. (BENCHIMOL, 1977, p. 173)

Assim, o caboclo vive da extração da castanha, da pesca do pirarucu, do cacau, da piaçava, retira da natureza o necessário para seu sustento. É essa realidade retratada na obra de Sousa.

No que diz respeito ao rio Amazonas basta dizer que naquela época, era um importante meio de acesso à Amazônia. Nesse período o homem vivia para o rio. Tudo: "a conquista, o povoamento, a fronteira, a economia, a alimentação, a vida gira em função do rio e da montaria" (BENCHIMOL, 1977, p.185). O rio, portanto, tem uma importância econômica e sociológica na vida dos amazônidas, que se adaptam as mudanças ocorridas nos períodos da cheia e da seca.

Fazia parte da cultura cabocla o desenvolvimento de ações (pescar, caçar, extração vegetal) voltadas para a própria subsistência. Por ser deste modo a forma de viver do caboclo é considerada primitiva, assim como dos indígenas. Para o colonizador, "estar longe do espaço europeizado significava estar situado num tempo passado, primitivo" (LOUREIRO, 2001, p. 41).

Essa ideologia, disseminada no período colonial que constitui a raiz cultural brasileira, não permitiu que a sociedade nativa se autovalorizasse. Ao contrário, se reconhecesse como constituída por uma raça inferior.

Sousa, era um profundo conhecedor da realidade amazônica, por isso retrata com propriedade o sofrimento do caboclo. Embora ele tenha deixado o Pará, sua terra natal, ainda adolescente, não deixou de manter contato com a região. É através do seu olhar que conhecemos o drama de José que aí representa tantos outros caboclos.

O autor faz outras críticas sociais no decorrer da narrativa, como se pode observar no trecho a seguir:

não cessam os livros de falar da grande fertilidade das nossas terras. Os autores desses livros não chegam a ver senão a superfície das coisas. Demais não conhecem as nossas condições de existência! Sabeis o que é ser pobre no Amazonas? É ser escravo [...]. Numa terra que não impera lei, numa terra que o governo despreza, quando devia cuidar grandemente dela, quem tem a força tem razão e direito [...]. (SOUSA, 2007, p. 67)

Embora a cultura cabocla seja predominante, pois representa a maior parte da população, ela ainda hoje é desvalorizada e rejeitada pelos poderes públicos.

No que diz respeito a linguagem, o livro traz um glossário, para facilitar o entendimento do texto, que possui inúmeras palavras comuns na região onde se passa a história e que retratam a cultura local. Eis alguns exemplos: regatões - vendedor que anda 
pelos rios de barco; xerimbabo - qualquer animal de estimação; salga - ato de salgar o peixe para conservação.

\section{O olhar do colonizador}

A relutância dos europeus em aceitar o que é diferente fez com que no ambiente colonizador eles rotulassem os nativos, de bárbaros. Criando o mito de superioridade racial, dessa forma, conseguindo estabelecer relações de poder entre colonizador e colonizado firmados numa ideologia de desqualificação e interiorização do dominado e superioridade do dominador. Para Bhabha, "os sujeitos do discurso são construídos dentro de um aparato de poder que contém nos dois sentidos da palavra, um "outro" saber - um saber que é retido e fetichista e circula através do discurso colonial como aquela forma limitada de alteridade que denominei estereótipo" (BHABHA, 1998, p. 120).

$\mathrm{Na}$ Amazônia não foi diferente, os europeus trataram de rotular os índios de indolentes e preguiçosos. De modo que indolência é um elemento utilizado pela teoria do determinismo geográfico, que influenciou a Literatura Naturalista, presentes na obra: "são sempre injustamente acusados os tapuios. Não se fartam de dizer que são indolentes e preguiçosos, que não se sabem aproveita dos vastíssimos recursos que lhes oferece a natureza!" (SOUSA, 2007, p. 67).

Gondim nos diz que "a preguiça também será usada como uma das justificativas da empresa colonialista em terras brasileiras, amazônicas, vista como um dos entraves de transformação regional. Trará também a ideia da inferioridade racial do norte brasileiro" (GONDIM, 1994, p. 57).

No seguinte trecho, do romance em questão, temos um exemplo do mito da superioridade racial, defendida pelos europeus. Vejamos: "o capitão era branco, e ele era tapuio. Havia, segundo o que lhe diziam todos, uma grande diferença, diferença incalculável, entre estas duas espécies de homens, quase a diferença entre o senhor e o escravo" (SOUSA, 2007, p. 55). Mais ainda uma demonstração da exploração do homem pelo homem.

A forma de dominação dos povos colonizados acontece, pela construção do "outro" através da degradação. Para Bhabha, "o objetivo do discurso colonial é apresentar o colonizado como uma população de tipos degenerados com base na origem racial de modo a justificar a conquista e estabelecer sistemas de administração e instrução" (1998, p. 120).

Com o intuito de estabelecer o poder sobre a população, o colonizador passa a utilizar estereótipos (para se referir as diferenças de raça e cultura) para designar a população colonizada, estabelecendo uma forma autoritária e discriminatória de domínio sobre a população. Em outro trecho do romance temos: "à noite acordou muitas vezes, sentido em si uma necessidade de atividade [...]. Até lhe parecia serem um furto feito ao capitão aquelas horas de repouso!" (SOUSA, 2007, p. 65). Fica explícito, nesta passagem o poder de dominação do capitão (colonizador) sobre José (colonizado). 
É importante lembrar que os estereótipos referentes à identidade amazônica, foram intensificados, a partir do final do século XIX, com a teoria Determinista, que se baseia na ideia de que o comportamento humano é determinado por três elementos: o meio, a raça e o momento histórico. Além da ideologia colonialista, em A História de um Pescador, podemos identificar característica do Determinismo de H. Taine, em que o meio molda à ação do homem, na obra as personagens são entregues à sucessão de fatos e às circunstâncias ambientais como se pode observar no trecho a seguir: "repito-vos, José era bom, uma ideia má dificilmente lhe passava pela cabeça. Foi preciso que sofresse muito para se tornar cruel e desapiedado como depois o foi" (SOUSA, 2007, p. 69). O homem nasce bom, o meio é que o corrompe, ideia que tanto influenciou a Literatura Naturalista.

\section{História de um Pescador}

A história do livro é ambientada na Amazônia, mais precisamente num pequeno sítio às margens do Igarapé de Alenquer, quase ao sair no Paraná-mirim de Baixo (de Óbidos/Grão-Pará). O Estado do Grão-Pará e Maranhão tinha como sede Belém e foi instituído em 1751, garantindo assim a soberania portuguesa na Amazônia.

O romance cuja primeira publicação data de 1876, está organizado em três partes. Na primeira, temos a apresentação da história de José, um tapuio filho de Benedita e Anselmo. A família mora em um pequeno sítio às margens do Igarapé de Alenquer e por influência do padre Samuel, José vai estudar em um colégio interno em Óbidos. Lá, permanece por quatro anos. Quando sua mãe vai visitá-lo para avisar da morte do pai, José foge do internato e volta com ela para casa.

A respeito dos anos passados no colégio, José achou uma perda de tempo, sentiase numa prisão, pensamento compartilhado por sua mãe, conforme nos esclarece o narrador:

para Benedita e o filho a estada deste em Óbidos não fora senão uma violência, que as circunstâncias tinham gerado, e que o padre Samuel completara, servindo-se habilmente do amor paterno de Anselmo Marques. Aqueles quatro anos perdidos no colégio tinham sido o sinal de uma vitória ganha pelos regatões (assim chamavam à gente da cidade) sobre os pobres matutos, e a fuga era a represália, a desforra tirada por estes. (SOUSA, 2007 p. 47)

José resiste à cultura colonialista que lhe é imposta pela figura do padre-reitor, que a todo custo buscava ensiná-lo "a amar a vida das cidades e a convivência social, não conseguiu mais do que firmá-lo nos seus primeiros sentimentos, aumentar-lhe as antigas antipatias, e tomá-lo completamente revel aos constrangimentos que impõe a sociedade" (SOUSA, 2007, p. 51).

Por outro lado, o protagonista, José, acaba se sujeitando ao capitão Fabrício, branco, rico proprietário de terras, trabalhando dia e noite para pagar uma suposta dívida deixada pelo pai. O jovem tapuio e a mãe levavam uma vida de privações. Todo fruto da pesca, caça e do cacau produzido em seu pequeno sítio eram entregues ao capitão. Assim, Souza apresenta uma discussão sociológica, em que trata da exploração do caboclo pelo 
homem branco. Na relação estabelecida entre eles existe uma dívida, que embora o jovem pescador entregue todo o fruto de seu trabalho por anos a fio, nunca é quitada. O branco se vê no direito de explorá-lo, por julgá-lo inferior. Essa relação de apoderamento sobre o outro é tanta que assim reflete no protagonista: "À noite acordou muitas vezes, sentindo em si uma necessidade de atividade, um desejo imenso de trabalho, que não o deixava fechar os olhos. Até lhe parecia um furto feito ao capitão aquelas horas de repouso!" (SOUSA, 2007, p. 65).

Temos, portanto, o personagem José como a figura do colonizado e o capitão Fabrício na figura de colonizador e detentor de poder sobre ele. Nos diálogos entre os dois, o capitão por diversas vezes se refere ao tapuio utilizando-se de termos como: vadio, preguiçoso e patife. Vejamos: "[...] Corja de vadios que não faz nada, e entende que há de viver à minha custa! Sempre acha uma desculpa para não pagar o que deve!" (SOUSA, 2007, p. 55). Assim, Fabrício mantém o domínio sobre José sugando o fruto de todo seu trabalho.

As ideias do progresso científico chegaram ao Brasil por volta de 1870, após ter avançado pela Europa, e rapidamente influenciou intelectuais brasileiros, dentre os quais destacamos Inglês de Sousa. O homem é uma máquina guiada por vários fatores: biológicos e social, além de estar vulnerável a forças incontroláveis. É o que acontece com José no seguinte excerto: "Criado nos severos e múltiplos princípios da religião católica que, auxiliados pelas suas superstições indígenas de toda a casta, se haviam apoderado da sua inteligência, o pescador do Igarapé tinha crenças puras, firmes e ingênuas. [...]”' (SOUSA, 2007, p. 98)

É possível verificar no romance vestígio do mito do bom selvagem. No romance, o pescador vivia com sua mãe, praticamente isolado e em harmonia com a natureza, mas o convívio com o meio social o transforma. O narrador na primeira parte do livro antecipa essa transformação pela qual a personagem irá passar: "Repito-vos, José era bom, uma ideia má dificilmente lhe passava pela cabeça. Foi preciso que sofresse muito para se tornar cruel e desapiedado como depois o foi" (SOUSA, 2007, p. 69). E ainda neste outro excerto: "- Depois digam que os tapuios são maus e perversos, que têm raiva dos brancos, e não sei mais o que... eles mesmos são os primeiros que atacam. Tenho fé em Deus que isto há de acabar, e um dia" (SOUSA, 2007, p. 149).

No trecho a seguir, vemos atribuída a raça à causa que determina ou interfere no comportamento de José: “... O capitão era branco, e ele era tapuio. Havia, segundo o que lhe diziam todos, uma grande diferença, diferença incalculável, entre estas duas espécies de homens, quase a diferença entre o senhor e o escravo" (SOUSA, 2007, p. 55). E a diferença racial entre o capitão e o tapuio está sempre em evidência no decorrer da narrativa.

Além disso, o pobre pescador tinha que se contentar com a sorte, pois tudo que estava acontecendo com ele era já estava pré-determinado. Como se pode observar no seguinte excerto:

[...] Como e por que ele as tinha contraído pouco importava ao filho. O dever deste era pagá-las, a sua miséria presente, o risco que correra afogando-se, o seu lidar sem repouso, tudo eram sofrimentos que Deus lhe impusera para experimentá-lo (e estava certo disso). Por isso o seu 
coração não tinha vislumbre de um ressentimento contra o capitão Fabrício. (SOUSA, 2007, p. 68)

Sousa traz para a Literatura, a denúncia social a respeito da exploração dos caboclos que vivem naquela região da Amazônia. Com o olhar de quem já presenciou, observou à realidade, ele revela sua indignação através do diálogo de duas peonagens (Gonçalo e Benevides), quando sabem da história de José. Um deles foi quem o resgatou da margem do rio entre a vida e a morte, após tentar evitar o sequestro de sua noiva pelo capitão Fabrício:

no Amazonas, me caro amigo, há duas espécies de homens. Os que mandam, que são os capitães, tenentes-coronéis, subdelegados e até inspetores de quarteirão, e os que são mandados, a população pobre e trabalhadora. São estes últimos que gastam as forças em um trabalho insano, são eles que fazem o pouco que vale o Amazonas, quanto A recompensa que recebem, o amigo tem um exemplo dela no desgraçado que caridosamente recolheu. O governo é o primeiro interessado em que dure esta erodem das coisas. (SOUSA, 2007, p. 195)

A Natureza também merece destaque, pois através dela o mundo pode ser explicado. Ainda a primeira parte tem a descrição de uma tempestade no Amazonas, fato também mencionado por outros escritores. Mas, nesta narrativa ela está associada ao drama de José, como que para dizer que o que ele passava não era um fato isolado, outros pescadores também viviam aquele contexto de exploração e quase escravidão que lhe impusera o capitão. Note-se o valor descritivo da cena:

Era uma dessas terríveis tempestades de verão, que surpreende o viajante, e que produzem medonhos efeitos. Nenhum peixe ousava botar para fora da superfície sua cabeça escura, nenhuma vela se divisava em toda vasta extensão das águas. (SOUSA, 2007, p. 58)

Ainda na primeira parte, o narrador nos fala do amor de José por Joaninha, realçando as qualidades da moça, que influenciada pela ideologia colonialista valoriza não o caboclo da terra, e sim o branco como homem ideal, uma vez que, financeiramente ele tem muito mais para oferecer: "às vezes parecia-lhe que a rapariga era uma volúvel, que só mereça desprezo; que como todas as da sua iguaria, se deixava levar facilmente pelo branco, o ideal de homem para elas [...]" (SOUSA, 2007, p. 91).

Embora, tenhamos na narrativa pequenos trechos com características do Romantismo, como no exemplo a seguir; "você não faz ideia do que me vai pelo coração. Eu já não durmo, nem como, nem bebo. Toda noite penso em você, Joaninha, quando estou à proa da montaria, com o arpão levantado, não é pirarucu que eu penso, é em você" (SOUSA, 2007, p. 77). Nota-se que o autor utiliza essa relação afetiva, que permeia grande parte da obra, para evidenciar a crueldade do capitão, que se valendo de sua condição social, quer a todo custo impedir o casamento de José com Joaninha. E, ainda por cima o capitão deseja tomá-la para si. O poder do colonizador (capitão) é tamanho que até impedir o pescador de casar-se com a mulher amada. $\mathrm{O}$ pobre infeliz pescador, não tem direito a nada, além de levar uma vida de escravo, cheio de privações, se vê impossibilitado de ficar com a mulher amada. A tristeza dele se converte em ciúme provando o desfecho obtido no romance. 
Na segunda parte do livro, Inglês de Sousa através do narrador traz uma série de informações sobre a cultura, os costumes amazônicos e o cotidiano ribeirinho. Dedicando dois capítulos para falar sobre a salga, que é o período do verão, no qual os pescadores (às vezes com a família) se dirigiam ao Lago Grande para pescar pirarucu. Lá formavam uma vila temporária onde passavam alguns dias ou até três meses. Por vezes, o narrador onisciente penetra no íntimo da personagem, para revelar seus sentimentos, vejamos:

De pé sobre a popa da montaria via José passar por perto a noiva no poder daqueles miseráveis, e estendia o braço para ela, como se pudesse libertá-la. O coração estalava-lhe com uma dor intensa. Soltou um brado horrível e caiu sentado no fundo da canoa, desfalecido, idiota pelo sofrimento. Toda a energia que o possuía momentos antes abandonou-o. (SOUSA, 2007, p. 127)

Também nesta parte o livro, temos a descrição de uma segunda tempestade, novamente associada ao drama de José. A natureza grandiosa e magnífica tem aí uma representatividade, uma relação imagética com o sofrimento de José que pode ser constatado na seguinte passagem: "A natureza toda tinha, porém, esse aspecto triste e sombrio que desperta a simpatia das almas dominadas por sua grande dor. A vegetação luxuriante, grandiosa, mas monótona e triste do Amazonas, tinha um aspecto desolador" (SOUSA, 2007, p. 130).

Dessa forma, corrobora com Holanda que afirma: "o espaço domina o horizonte amazônico, como o meio age sobre o homem na estética naturalista, como se o espaço regional fosse, em termos simbólicos, uma validação geográfica do determinismo naturalista" (HOLANDA, 2007, p. 10).

No terceiro e último capítulo, José entre a vida e morte depois de tomar um tiro dos empregados do capitão que levaram sua noiva, passa horas flutuando num capinzal pelo rio. Gonçalo Bastos o socorre, ajudado pelo médico peruano, Dr. Benevides. Reaparece a figura do Padre Samuel, seu padrinho e bem-feitor que aponta o sacerdócio como única oportunidade para o pescador melhorar de vida. José passa meses entre a vida e a morte, sem saber notícias de sua amada. Depois de recuperado ele resolve, então, procurá-la.

\section{Considerações finais}

O homem da Amazônia depende da floresta e do rio para quase tudo, deles tira seus sustento e sobrevivência, usufruindo seus bens. José representa muito bem o caboclo solitário que percorre o rio, os igarapés, os inúmeros furos e ilhas do rio Amazonas, em suas margens pouco povoadas. Passando horas e horas, sozinho em busca de peixes. Isso sem falar da imensidão verde, que margeia o rio. O rio também é ligação do homem amazônico com mundo, por ele se vai à cidade, aos sítios vizinhos. É por tudo isso que a Amazônia despertou, e ainda desperta interesses de estudiosos e viajantes, no passado e nos dias atuais. Isto porque,

não obstante ser uma das regiões mais definidas e individualizadas dentro dos quadros continentais, a Amazônia não é, contudo, uma região 
fácil de definir e delimitar, a começar pela plurivalência de sentido do termo que a nomeia, que tanto pode significar uma bacia hidrográfica como uma província botânica, um conjunto político como, espaço econômico. (LOUREIRO, 2001, p. 69)

Sousa contribui para uma maior compreensão, desta região que ainda hoje é marcada pela violência, disputa de terras, exploração, em que os povos ribeirinhos continuam abandonados pelo poder público, entregues à própria sorte. Mas apesar de tudo, o caboclo resiste, assim como o pescador do romance. A obra revela uma grande importância sociológica, por tratar da exploração do ribeirinho pelo colonizador, nas figuras do pescador e do capitão.

O autor utiliza o poder descritivo em vários momentos do romance para revelar os personagens e a paisagem amazônica. Temos, no decorrer da narrativa, várias palavras regionais, que na edição em estudo, conta com um glossário elaborado pela UFPA, com o objetivo de facilitar o entendimento do texto.

É possível, relacionar a trajetória de José, ao mito de Orfeu quando no dia de seu casamento, Eurídice, sua noiva, caminhava pelas margens do rio, de repente apareceu Aristeu, que tentou violentá-la. No desespero de se livrar do atacante, ela pisou numa serpente escondida na vegetação e morreu depois de ser picada. No livro analisado, o pescador, ao tentar salvar a amada é baleado e desce pelo rio preso num capinzal, beirando a morte, sozinho.

Portanto, Sousa faz um panorama da Cultura amazônica utilizando dos elementos da Literatura Naturalista, que justificam o comportamento do protagonista. Caracterizado como um homem bom, trabalhador, explorado pelo branco, passa por uma série de situações que vão justificar sua atitude violenta no final do romance.

Temos um esboço da identidade cabocla, contrapondo com os estereótipos colonialistas de que o povo da Amazônia é preguiçoso ou indolente. Sousa denuncia a situação de exploração e de abandono vivenciados nas comunidades mais remotas da Amazônia.

Uma obra que sem dúvidas, deveria figurar entre os cânones da Literatura, pois em nada deixa dever. Uma forma de valorizar a cultura local, como bem vem fazendo a Universidade Federal do Pará, reeditando os livros de Inglês de Sousa, tornando assim acessível sua leitura. Vale a pena voltar o olhar para este autor da Amazônia, que soube falar sobre ela com propriedade.

O conceito de "identidade" aqui deve ser entendido não como algo acabado, terminado, mas como um processo, a identidade não é algo que se encerra em uma noção dada previamente, mas sim "algo que se constrói enquanto o sujeito compartilha, enquanto está posto em relação, nos levando a pensar nesse processo sempre em interface com a alteridade" (BOECHAT, 2011, p. 16). Portanto, nesse sentido, a Amazônia sempre teve uma identidade, mesmo quando não havia a predominância do idioma e cultura portugueses, afinal os variados povos que viviam nestas terras comprovam o compartilhamento, a construção de culturas e a citada "interface com a alteridade". A preocupação com uma "identidade regional" aflorou quando surgiu uma população mestiça e esta divergiu, dialeticamente e fisicamente, com o poder centralizador da 
administração do Estado brasileiro. Essa preocupação, em um primeiro momento, estaria muito mais atrelada aos interesses administrativos do Estado. Devido à escassez da mão de obra portuguesa para tarefas na colônia, não predominou um conceito de identidade baseado nos valores europeus, pois na Amazônia "havia predominância do índio sobre o negro e o branco. E, evidentemente, dos caboclos, isto é, mestiços descendentes de índios e brancos" (LOUREIRO, 2000, p. 28). É, pois, um local de choque cultural. Os conflitos internos, as entradas do africano e do europeu fizeram a região rica em dialetos e etnias. Unificar isso sob o jugo da língua e cultura portuguesas tornou-se tarefa dantesca, principalmente em relação às culturas amazônicas, pois prevaleceu nestas a miscigenação, o sincretismo religioso, a difusão de mitos e lendas africanas e europeias que se misturaram aos de origem indígena, formando algo original e complexo. E foi esse amálgama de raças e crenças que fez surgir o povo local, muitas vezes unido pela pobreza, perseguição e problemas políticos locais. E essa formação foi tortuosa até mesmo em relação à expressão literária nacional, é o que afirma Cândido (1999) ao comentar o surgimento da literatura no Brasil colônia.

\section{Referências bibliográficas}

BENCHIMOL, S. Amazônia: um pouco-antes e além-depois. Manaus: Ed. Alberto Calderaro, 1977.

BHABHA, H.K. O Local da Cultura. Belo Horizonte: Editora UFMG, 1998.

CANDIDO, Antonio. Crítica e Sociologia. Em: Literatura e sociedade. $11^{\mathrm{a}}$. ed. Rio de Janeiro: Ouro sobre azul, 2010.

GONDIM, Neide. A invenção da Amazônia. São Paulo: Marco Zero, 1994.

HALL, Stuart. A identidade cultural na pós-modernidade. Trad. Bras. 11 a . ed. Rio de Janeiro: DP\&A, 2011.

HOLANDA, S. Prefácio. Em: SOUSA, Inglês de. História de um Pescador. Belém: EDUPA, 2007

LOUREIRO, João de Jesus Paes. Cultura Amazônica: uma poética do imaginário. São Paulo: Escrituras, 2001.

SOUSA, H. Inglês de. História de um Pescador. Belém: EDUFPA, 2007.

Artigo recebido em: outubro de 2016.

Aprovado e revisado em: dezembro de 2016.

Publicado em: abril de 2017. 


\section{Para citar este texto:}

RIBEIRO, Ana Cláudia Dias. Um olhar sobre a Amazônia na obra História de um pescador, de Inglês de Sousa. Entremeios [Revista de Estudos do Discurso, on-line], Seção Estudos, Programa de Pós-Graduação em Ciências da Linguagem (PPGCL), Universidade do Vale do Sapucaí (UNIVÁS), Pouso Alegre (MG), vol. 14, p. 63-74, jan. - jun. 2017.

DOI: http://dx.doi.org/10.20337/ISSN2179-3514revistaENTREMEIOSvol14pagina63a74 